$$
\therefore
$$

NASA Technical Memorandum 102617

\title{
USING TRANSONIC SMALL DISTURBANCE THEORY FOR PREDICTING THE AEROELASTIC STABILITY OF A FLEXIBLE WIND-TUNNEL MODEL
}

Walter A. Silva and Robert M. Bennett

March 1990

(NASA-TM-102017) USING TPANSONIC SMALL

$N 90-20047$

UISTURSANCE THEORY FOR PREUICTING THE

AFROLLASTIC STA?ILITY OF A FLEXIOLE

WINTTUNNEL MODFL (NASA) $13 \mathrm{P}$ CSCL OIA UNCIAS

G3/02 0271137

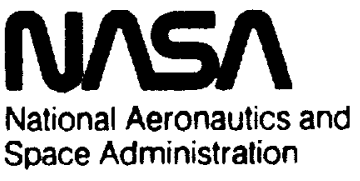

Langley Research Center

Hampton, Virginia 23665-5225 
$+\overline{4}$ 


\title{
USING TRANSONIC SMALL DISTURBANCE THEORY \\ FOR PREDICTING THE AEROELASTIC STABILITY \\ OF A FLEXIBLE WIND-TUNNEL MODEL
}

\author{
Walter A. Silva* \\ Lockhecd Engincering and Sciences Company \\ Hampton, VA 23666
}

and

Robert M. Bennelt**

Unstcady Acrodynamics Branch

NASA Langley Research Center

Hampton, VA 23665-5225

\begin{abstract}
The CAP-TSD (Computational Acroelasticity Program - Transonic Small Disturbance) code, developed at the NASA - Langley Research Center, is applied to the Active Flexible Wing (AFW) wind-tunnel model for prediction of the model's transonic acroclastic bchavior. Static aeroelastic solutions using CAP-TSD are computed. Dynamic (flutter) analyses are then performed as perturbations about the static acroclastic deformations of the AFW. The accuracy of the static acroclastic procedure is investigated by comparing analytical results to those from previous AFW wind-tunnel cxperiments. Dynamic results are presented in the form of root loci at different Mach numbers for a heavy gas and air. The resultant flutter boundaries for both gases are also presented. The effects of viscous damping and anglc-ofattack, on the flutter boundary in air, are presented as wcll.
\end{abstract}

\section{INTRODUCTION}

An understanding of the acroclastic behavior of flight vehicles in the transonic regime is of great importance for flight safety. For example, it is well known that aircraft nying into or through the transonic regime may encounter a region of reduced flutter speed known as the transonic flutter dip. Valuable insight into the nature of this transonic flutter dip phenomena is provided by Isogai ${ }^{1}$ for a two-dimensional airfoil, while comparison of acrodynamic theory with the experiments reported by Davis and Malcolm ${ }^{2}$ reveal the limitations of lincar theory applicd in the transonic regime. Linear acrodynamics, although highly successful in the subsonic and supersonic regimes, cannot normally be used to accurately predict Iransonic acroclastic behavior, Transonic flow equations capable of modelling flow

\footnotetext{
* Principal Engincer, Mcmber AIAA.

**Senior Research Engincer, Unsteady

Acrodynamics Branch, Associatc Fcllow AIAA.
}

nonlincaritics (shocks, boundary layer, separation and vorticity) and boundary condition nonlinearities (airfoil thickness and shape, and large deflections) must then be solved. The surveys by Edwards and Thomas ${ }^{3}$ and Ballhaus and Bridgeman ${ }^{4}$ review recent computational developments in the ficld of transonic aeroelasticity. Some of these devclopments include modelling of the Navier-Stokes cquations 5 and the Euler equations ${ }^{6}$ for flutter analysis. Application of these higher order formulations, however, has primarily been limited to twodimensional configurations, due to the large computational costs incurred. Certain assumptions regarding the flow can be made to yield reduced order formulations such as the full-potential equation ${ }^{7}$ and the computationally efficient transonic small-disturbance (TSD) equation. Research efforts involving the TSD formulation include the development of the XTRAN3S $\operatorname{code}^{8}$, the work by Yang, Guruswamy, and Striz ${ }^{9}$, and many others.

A transonic aerodynamics code known as CAP-TSD (Computational Acroclasticity Brogram-Transonic S-mall Disturbance) has been developed at the NASA - Langley Research Center (LaRC). CAP-TSD is capable of handling multiple lifting surfaces with control surfaces, bodies (nacelles, pylons, stores), vertical surfaces, and a fusclage, and solves the TSD equation using an efficient approximate factorization scheme ${ }^{10}$. References 11-12 verificd the code's ability to accurately predict steady and unstcady pressures for wings and configurations at subsonic, transonic, and supersonic Mach numbers. Flutter prediction using CAP-TSD for two thin, sweptand-tapered wings compared well with experimental flutter results ${ }^{13}$. The goal of the present study was to define the transonic flutter boundary of the Active Flexible Wing (AFW) wind-tunnel model 14,15, for use as guidance during flutter testing, and to evaluate CAP-TSD's flutter prediction capability for a complete and realistic aircraft configuration.

The Active Flexible Wing (Fig. 1) model is a fullspan, sting-mounted wind-tunnel model designed and built by the Rockwell International Corporation. The main 
ORIGINAL PAGE

\section{BLACK AND WHITE PHOTOGRAPH}

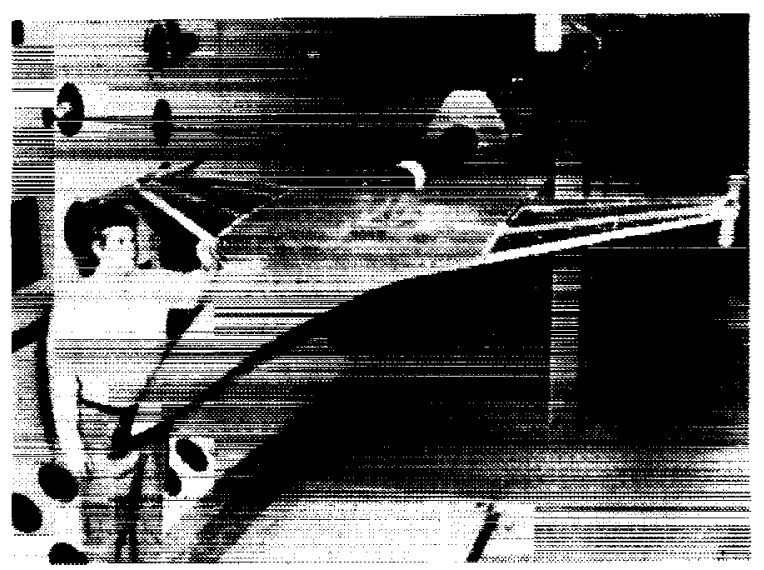

Fig. 1 The AFW in NASA-LaRC's Transonic Dynamics Tunnel (TDT).

goal of the present AFW project is to design, implement and validate digital control laws for flutter suppression 16 and roll maneuver load alleviation. A priori knowledge of possible regions of instability are, therefore, crucial.

This paper first presents the computational procedures incorporated in CAP-TSD. This includes a brief description of the TSD formulation and the coupled aerodynamic and structural equations of motion that are integrated in time. These equations are used for both static acroelastic and dynamic analyses of the AFW. An important conclusion of the studies by Yates, Wynne, and Farmer ${ }^{17}$ and Yates and Chu ${ }^{18}$ was that the accuracy of the transonic flutter prediction is highly dependent on the accuracy of the static aeroclastic state of the wing. As a result, a procedure for computing static acroelastic deformations is presented. The dynamic bchavior is computed as a perturbation about previously computed static acroelastic solutions. The resultant dynamic time histories of the generalized displacements are then analyzed using a modal identification technique to estimate the stability parameters (root locus) of the system at a given Mach number and dynamic pressure. Dynamic results arc presented in the form of root locus excursions at different Mach numbers in a heavy gas (Freon-12) and in air. Flutter boundarics for the heavy gas and air, variations in angle-of-attack and viscous damping, and comparisons with experimental flutter results are also presented.

\section{COMPUTATIONAL PROCEDURES}

In this section, an overvicw of the computational procedures is presented including a description of the CAP-TSD program, the acroclastic equations of motion, the time-marching solution of these equations, and the modal identification of the resulting free decay transients.

\section{CAP-TSD Program}

The CAP-TSD program is a finite-difference program which solves the general-frequency modified transonic small-disturbance (TSD) equation. The TSD potential equation is defined by

$$
\begin{aligned}
& M_{\infty}^{2}\left(\phi_{t}+2 \phi_{x}\right)_{t}= {\left[\left(1-M_{\infty}^{2}\right) \phi_{x}+F \phi_{x}^{2}+G \phi_{y}^{2}\right]_{x}+} \\
&\left(\phi_{y}+H \phi_{x} \phi_{y}\right)_{y}+\left(\phi_{z}\right)_{z}
\end{aligned}
$$

where $M_{\infty}$ is the Mach number and $\phi$ is the disturbance velocity potential.

Several choices are available for the coefficients $F$, $G$, and $H$ depending upon the assumptions used in deriving the TSD equation. For transonic applications, the coefficients are herein defined as

$$
\begin{aligned}
& F=-\frac{1}{2}(\gamma+1) M_{\infty}^{2}, \\
& G=\frac{1}{2}(\gamma-3) M_{\infty}^{2}, \\
& H=-(\gamma-1) M_{\infty}^{2}
\end{aligned}
$$

The linear potential equation is recovered by simply setting $F, G$, and $H$ equal to zero.

Equation (1) is solved within CAP-TSD by a timeaccurate approximate factorization (AF) algorithm developed by Batina 10 . In Refs. 10 to 12 , the $A F$ algorithm was shown to be efficient for application to steady or unsteady transonic flow problems. It can provide accurate solutions in only several hundred time steps yielding a significant computational cost savings when compared to altemative methods. Several algorithm modifications have been made which improve the stability of the $A \bar{F}$ algorithm and the accuracy of the results 19,20 . The CAP-TSD program can treat configurations with combinations of lifting surfaces and bodies including canard, wing, tail, control surfaces, tip launchers, pylons, fuselage, stores, and nacelles.

The configuration capability of the current version of CAP-TSD permits the calculation of pressures on the fuselage and bodies. In the present study, modal perturbations of the fusclage and bodies are not included in the boundary conditions and the integration of the pressures for the gencralized acrodynamic forces of the fusclage and bodies are not included in the aeroclastic solution. However, the aerodynamic influence of both the fuselage and wing tip body of the AFW model are included as interference effects upon the wing pressures.

\section{Equations of Motion}

The acroclastic equations of motion are based on a right-hand orthogonal coordinate system with the $x$ direction defined as positive downstream, y-direction positive out the right wing, and the $z$-direction positive upward. The equations of motion may be written as

$$
M \ddot{q}+C \dot{q}+K q=Q
$$


where $q$ is a vector of generalized displacements, $M$ is the generalized mass matrix, $C$ is the damping matrix, and $K$ is the stiffness matrix. $Q$ is the vector of generalized forces where its elements arc defined by

$$
Q_{i}=\frac{\rho U^{2}}{2} c_{r}^{2} \int_{s} \frac{\Delta p h_{i}}{\rho U^{2} / 2} \frac{d S}{c_{s}^{2}}
$$

and $\Delta p$ is the lifting pressure, $\rho$ is the fluid density, $c_{r}$ is the root chord, $U$ is the freestream velocity, $S$ is the area of the lifting surface(s) and $h_{i}$ is the vibration mode shape. Equation (3) is rewritten as

$$
\ddot{q}=-M^{-1} K q \cdot M^{-1} C \dot{q}+M^{-1} Q
$$

to permit integration of the equation with respect to timc.

\section{Time-Marching Aeroelastic Solution}

The aeroelastic solution procedure implemented within CAP-TSD for integrating Eq. (4) is similar to that described by Edwards, Bennett, Whitlow, and Seidel 21 . Equation (4) is composed of normal mode equations which may be expressed in lincar, first-order state-space form as

$$
\dot{x}_{i}=A x_{i}+B u_{i}
$$

$$
\begin{aligned}
& \text { where } \\
& \begin{aligned}
x_{i} & =\left[\begin{array}{ll}
q_{i} & \left.\dot{q}_{i}\right]^{T}
\end{array}\right. \\
\text { and } & =\left[\begin{array}{cc}
0 & 1 \\
-m_{i}^{-1} k_{i} & -m_{i}^{-1} c_{i}
\end{array}\right] \\
B & =m_{i}^{-1} \frac{\rho U^{2}}{2} c_{r}^{2}\left[\begin{array}{c}
0 \\
1
\end{array}\right] \\
u_{i} & =\int_{s}^{\Delta C_{p} h_{i} d S / c_{r}^{2}} \\
\Delta C_{p} & =\frac{\Delta p}{\rho U^{2} / 2}
\end{aligned}
\end{aligned}
$$

In these definitions, $m_{j}, c_{i}$, and $k_{i}$ are elements of the mass, damping, and stiffness matrices, respectivcly, corresponding to mode $i$. The analytical solution to Eq. (5) and a description of its numerical implementation in CAP-TSD is found in Refs. 13 and 21.

For aeroelastic analysis, two steps are generally required in performing the calculations. In the first stcp, the steady-state flow field is calculated to account for wing thickness, camber, mcan angle-of-attack, and static acroelastic deformation, thus providing the starting flow field for the dynamic acroclastic analysis. Previously published CAP-TSD flutter studies analyzed only symmetric airfoils at zcro angle-of-attack ${ }^{13}$, thereby avoiding the problem of static aeroelastic deformations. For the AFW, the wing is unsymmetric and rigged at a non-zero angle-of-attack, so a procedure for computing static aeroelastic solutions had to be developed before an accurate dynamic analysis could be performed. The dynamic analysis would then be a perturbation about a converged static acroelastic solution at each Mach number and dynamic pressurc of interest.

The procedure developed and applied in this study for computing static aeroelastic deformations is to allow the structure and aerodynamics to interact with no initial excitation (no initial deflection or velocity) and with a large value of viscous damping to prevent divergence of the solution. This method resulted in convergence of the generalized displacements. Static aeroelastic deformations should be independent of viscous damping and different values of viscous damping $(\zeta=.375, .707$, and .99) were evaluated. A typical result for this type of analysis is presented in Fig. 2, which shows a representative variation of a generalized displacement as a function of computational time steps for three values of viscous damping. It is clear from Fig. 2 that the convergence is indeed independent of the value of viscous damping.

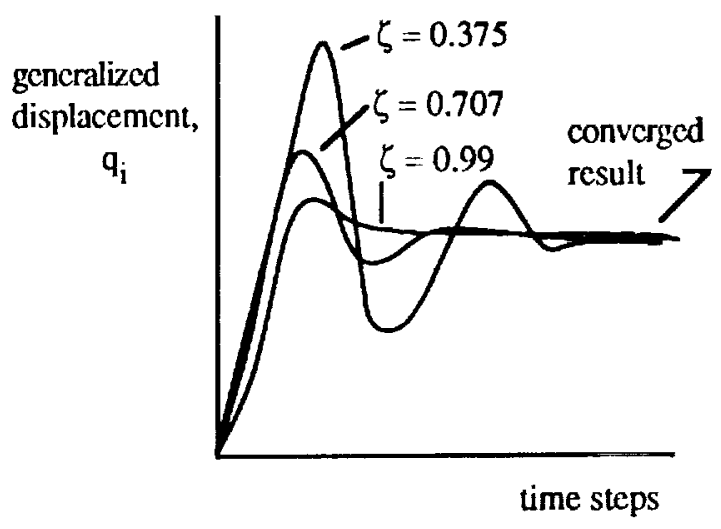

Fig. 2 Convergence of gencralized displacements for different values of viscous damping.

Furthermore, the larger the value of viscous damping, the faster the convergence. Therefore, the highest value of viscous damping $(\zeta=0.99)$ was used in order to accelerate the static aeroelastic solution. For the applications presented herein, 1000-2000 time steps were used to converge the static aeroelastic solutions. An interesting result of this procedure is that it allows the computation of static aeroclastic deformations at dynamic pressures above the flutter dynamic pressure for the AFW.

Once converged static aeroelastic solutions are computed, the next step is to prescribe an initial disturbance to begin the dynamic structural integration. 
Disturbance (or modal) velocities in the first three modes are used as initial perturbations. About 7 cycles of the lowest frequency (first) mode were needed for accurate modal identification. For a constant, non-dimensional time step of .01 , this required 4000 time steps in the heavy gas and 8000 time steps in air. In determining a flutter point, the freestream Mach number, $M_{\infty}$, and the associated freestream speed, $U$, were held fixed. A value of the dynamic pressure $\rho U^{2} / 2$ is then used and free decay transients are computed. These resulting transients of the generalized coordinates are analyzed for their content of damped or growing sine-waves, with the rates of growth or decay indicating whether the dynamic pressure is above or below the flutter value. This analysis then indicates whether to increase or decrease the value of dynamic pressure in subsequent runs to determine a neutrally stable result.

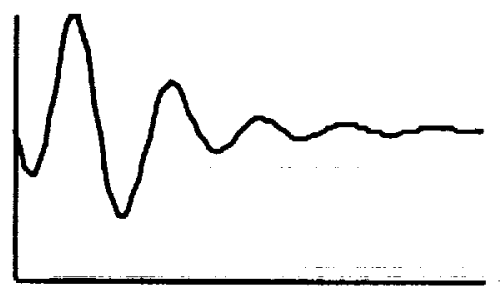

a) complex decay record

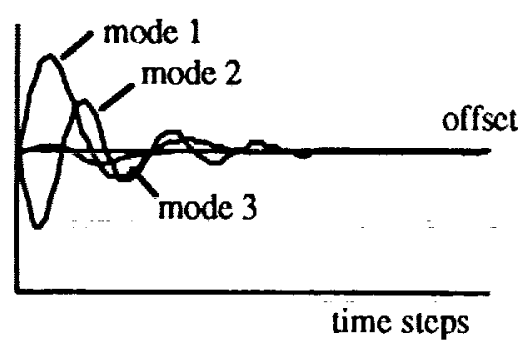

b) identified modal components and offset

Fig. 3 Example of dynamic decay record and its modal components.

\section{ModaL_Identification}

As previously mentioned, CAP-TSD generates frec decay transients that must be analyzed for the modal stability characteristics. A typical transient for the AFW model, calculated using CAP-TSD is shown in Fig. 3(a). The first three modes used in the analysis were excited by specifying an initial condition for cach modal velocity to produce a complex decay record. This record is analyzed using a lcast-squares curve-fit of the response data with complex exponential functions. The program utilized is a derivative of the one described in Ref. 22 . The components of the transient of Fig. 3(a) are plotted in Fig. 3(b) to the same scale. The free decay properties of each mode for this condition are readily apparent and the mean or offset value is the static acroelastic deformation of the mode being analyzed. A sufficient range of dynamic pressure must be considered to determine all relevant flutter points.

\section{ANALYSIS AND RESULTS}

\section{CAP-TSD Computational Model}

The AFW geometry data was obtained from Rockwell International, including detailed airfoil shape information. From this geometry data, a half-span model, with symmetry specified at the centerline, was generated. This CAP-TSD model consists of a fuselage, the addition of the region aft of the main wing and next to the fuselage referred to as the coat-tail, the main wing with all four control surfaces, and the wing tip ballast store. The grid dimensions for this model are $134 \times 51 \times 62$ in the $x-, y-$, and z-directions respectively for a total of 423,708 grid points. The grid extends 10 root chords upstream, 10 root chords downstream, 2 semi-span lengths in the $y$ direction, and 10 root chords in the positive and negative $z$-direction. Modelling of the wind-tunnel sting mount is done by extending the computational fuselage aft to the downstream boundary. The grid density is increased in regions where large changes in the flow are expected, such as at the leading edge, trailing edge, wing tip, and control-surface sides and hinge lines. The four control surfaces are the leading-edge inboard (LEI), leading-edge outboard (LEO), trailing-edge inboard (TEI), and trailingedge outboard (TEO). Each control surface has a chord that is $25 \%$ of the local chord and a span that is $28 \%$ of the semi-span. The airfoil definition includes the control surface actuator bumps on the outboard half of the wing. There also exist slight discontinuities on the wind-tunnel model where wing box and control surfaces meet (at the quarter- and three-quarter chord). These discontinuities are not included in the analytical model because of potential numerical difficulties. The effect of the actuator bumps and the control surface/wing box discontinuitics on the measured and computed static pressure distributions will be presented in a subsequent section. A computergencrated picture of the CAP-TSD model of the AFW is shown in Fig. 4. Although not shown in the figure, a

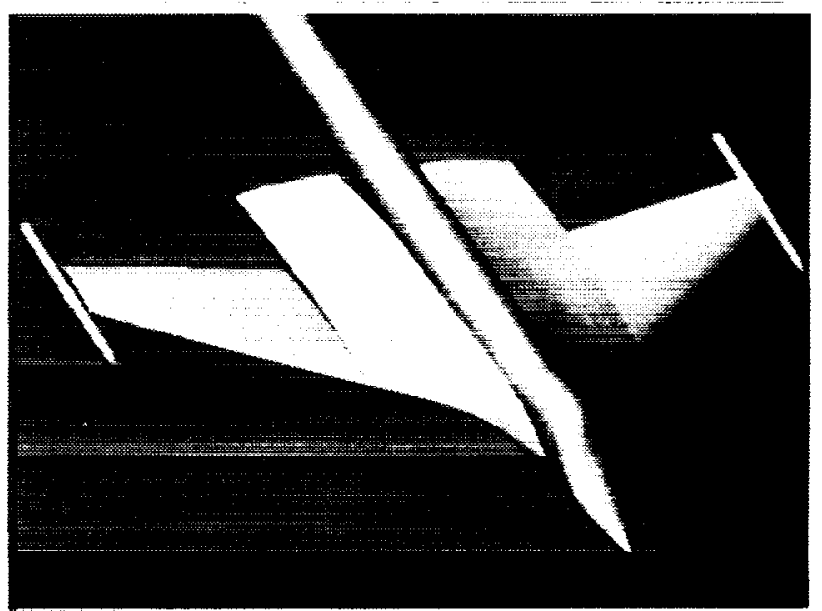

Fig. 4 CAP-TSD computational modcl of the AFW. 
protrusion on the underside of the fusclage that houses the model's pitch actuator is also included in the analytical model.

Analytical modes and frequencies were oblained from a finite-element model and separated into symmetric and antisymmetric modal data sets. The flutter analysis was performed using analytical mode shapes with measured frequencies (ground vibration test). The symmetric data was shown by linear analysis 15 to be the most flutter critical in the higher, subsonic Mach number regime and so only these were analyzed in the present study. A total of eight symmetric modes were included in the model. The interpolation of mode shape displacements and slopes at the computational grid points is done via a surface spline ${ }^{23}$. Each structural section was splined separately and then recombined to form the necessary input to CAPTSD. The separate structural sections are the wing box, coat-tail, and the four control surfaces. Slender bodies such as the fuselage and tip ballast store are not given any modal definition in CAP-TSD, as was previously mentioned, therefore no modal data was necded for thesc components.

\section{Static Aeroelastic Results}

The accuracy of the static acroclastic solution can be determined by comparing analytical results with existing experimental data. There were three sets of experimental data, from the previous AFW tests in the heavy gas, available for this purpose. This data included: 1) pressure coefficient distributions; 2) control-surface effectivencss parameters; and 3) static deflection data computed from experimental pressure distributions due to control-surface deflections ${ }^{14}$. It should be noted that the comparisons with the second and third sets of experimental data are not a direct assessment of the static aeroelastic procedure alone, since the accuracy of the control surface modelling within CAP-TSD is obviously an integral part of the result. Static deformation data with no control surface deflection is desirable, but, unfortunately, not readily available. Both sets of data, however, are uscful in observing the trends and behavior of the static acroelastic procedurc as wcll as the control surface modelling within CAP-TSD. Note that the AFW configuration for these previous tests did not include the tip ballast store used in the recent test. For the CAPTSD calculations to compare with the earlier experiments, the tip ballast store was deleted and the tip fairing added.

Pressure distributions- Figurc 5 presents pressure coefficient distributions versus percent chord for CAP. TSD and experiment at $M_{\infty}=0.9$ and a dynamic pressure, $q$, of $150 \mathrm{psf}$ at the three span stations shown, where $\eta$ is the percent semi-span.

The overall agreement between analysis and experiment is good, with some discrepancics occuring near the trailing edge and wing tip. The first two span stations compare remarkably well from the leading cdge up to about sixty percent of the local chord. Sudden changes in the flow can be secn near the quarter-chord at the second span station and near the three-quarter chord for all thrce span stations. These disruptions in the flow may be caused by the previously-mentioned physical discontinuities where wing box and control surfaces meet. At the second and third span stations, the effect of the actuator bumps on the lower surface pressures is evident. Agreement between analysis and experiment deteriorates at the third span station, possibly due to separated and/or tip vortex flow around the wing tip region.

Analytical and experimental pressure data were also compared at a lower dynamic pressure ( $q=36 \mathrm{psf}$ ) although not presented herein. Since the static aeroelastic deformations at the higher dynamic pressure $(\mathrm{q}=150 \mathrm{psf})$ are larger than at the lower dynamic pressure ( $q=36 \mathrm{psf}$ ), the results at the higher dynamic pressure (Fig. 5) provide a morc stringent test of the static aeroelastic procedure. Surprisingly, there exists an overall improvement in correlation betwecn analytical and experimental pressure distributions at the higher dynamic pressure. This is possibly due to the ract that at the higher dynamic pressure, the flow tends to remain attached over a larger portion of the wing than at the lower dynamic pressure, creating a condition that is closer to the TSD assumptions of inviscid, attached flow.

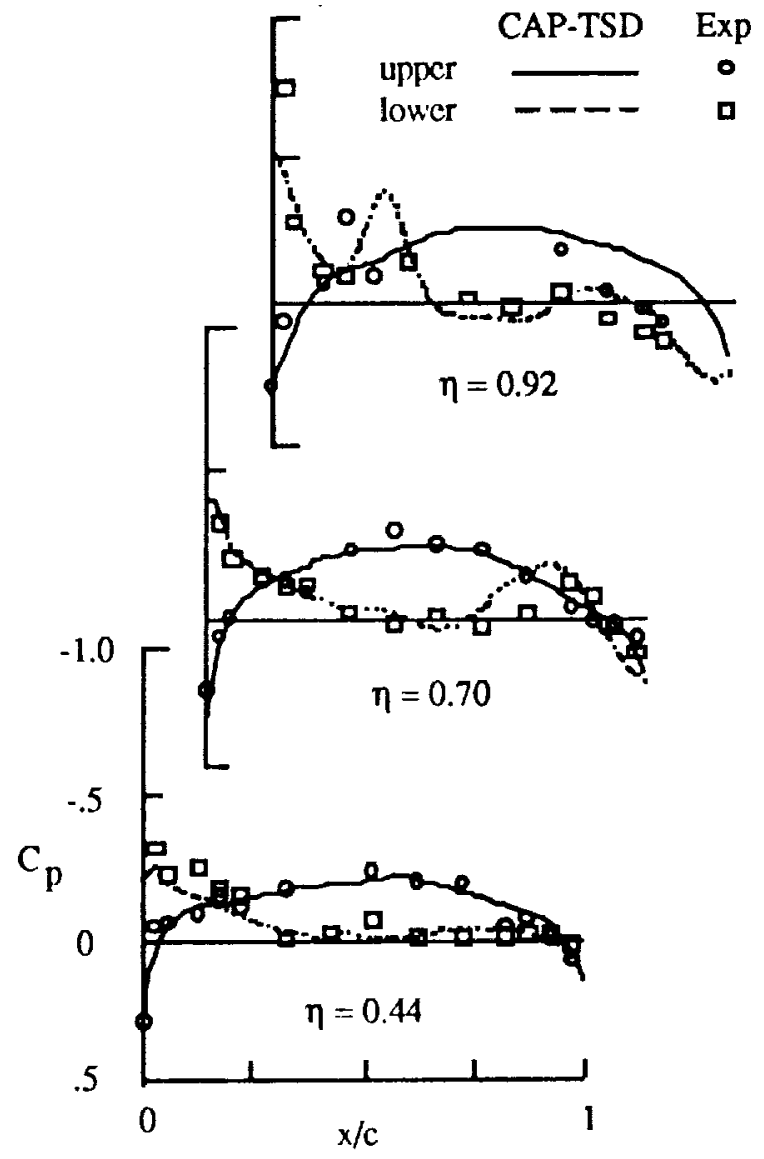

Fig. 5 Comparison of pressure distributions at $\mathrm{M}_{\infty}=0.9$ and $q=150$ psf in the heavy gas. 
At $\mathrm{M}_{\infty}=0.95, \mathrm{q}=36 \mathrm{psf}$, the analytical and measured pressure distributions differ significantly (not shown here), specifically, in the shock strength and location. Typical for isentropic, inviscid flow theory, the shock is predicted too far aft and too strong when compared with experimental results. Even the use of vorticity and entropy corrections in the analysis did not improve the results significanily. There are cvidently other nonlinear flow effects (separation, boundary layer) and a greater sensitivity to differences in the computational and physical airfoil shape that weaken the comparison at this test condition.

Control-surface effectiveness- For the controlsurface effectiveness parameters, the present study investigates only the lift coefficient due to control-surface deflection for all four control surfaces at one Mach number and dynamic pressure. This was not meant to be an extensive investigation into the control surface capabilitics of CAP-TSD as a detailed analysis of this capability would require a grid convergence study to determine the effects of varying grid densities in the vicinity of the control surfaces' sides and hinge lines. Furthermore, with deflected controls, boundary layer effects are expected to be significant and affect the effectiveness of the controls whereas the current calculations are for inviscid, attached flow.

The analysis was performed in much the same way that the data was measured in the wind tunncl. For cach control surface deflection, the model was allowed to converge to a static aeroclastic solution and the resulting
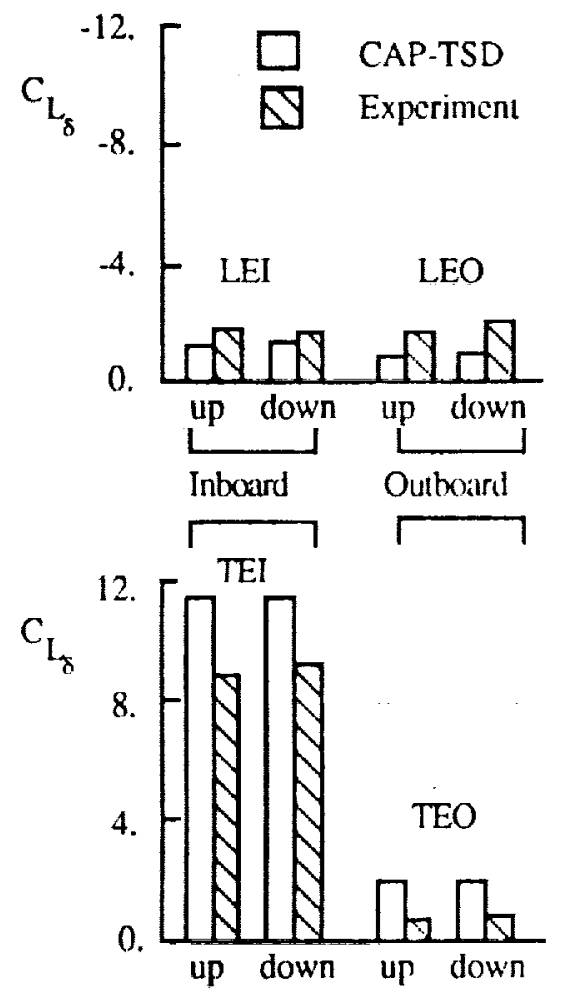

Fig. 6 Control surface effectiveness, $M_{\infty}=0.9$, $\mathrm{q}=150 \mathrm{psf}$ in the heavy gas. lift coefficient was recorded. Expcrimental data was availablc at $+5,-5$, and 0 degrees of control surface deflection. Figure 6 presents the comparison between CAP-TSD and expcrimental control surface effectiveness parametcrs for all four control surfaces at $M_{\infty}=0.9$ and $q=150 \mathrm{psf}$.

It can be scen that the trailing-edge controls are analytically more cffective than the experimental results, whilc the leading-edge controls are analytically less effective. It is quite possible that at the leading-edge, vortex flows induced by the control surface deflections are enhancing the experimental effectiveness of the control surfaces. At the trailing edge, however, separated and boundary layer flows may be reducing the measured control surface effectiveness, most noticeably outboard. The fact that the LEI control surface correlates the best with expcriment at this Ilight condition is consistent with the fact that the best pressure correlations are at the leading edge and inboard of the wing. The TEI control surface results are surprisingly good, mostly due to the large loads generated by this surface, thereby reducing the relative error. Comparison between analysis and experiment for the TEO control surface is poor, probably duc to viscous (boundary layer) and tip vortex flows, not modelled in TSD theory.

In general, the prediction of control surface effectiveness parametcrs by CAP-TSD can qualitatively identify the most effective (TEI) and least effective (TEO) control surface, but improvement is needed for quantitative prediction.

Static Aeroelastic Deflections- The third and final sct of data is static acroelastic deflections. In order to determine wing deflections, a distributed, coarse grid of vertical forces using experimental pressure distributions was computed ${ }^{14}$. These forces were then multiplied by the model's measured structural flexibility matrix to obtain wing deflections. These deflections are therefore quasi-experimental, since they were not measured directly. The CAP-TSD wing deflections were computed by the summation of the products of each converged generalized displacement (from the static aeroelastic solution) with its corresponding mode shape. Figure 7 gives the comparison of the quasi-experimental and the CAP-TSD wing deflections along the chord, or wing station, at three spanwise locations due to a TEO deflection of plus five degrees (trailing-edge down) at $M_{\infty}$ $=0.9, q=150 \mathrm{psf}$. It should be mentioned that these arc the resultant modal deflections and not the actual shape of the wing, since the latter should include the downward deflection of the TEO control surface.

The larger analytical deflections are consistent with the larger analytical loads predicted for the TEO control surface (Fig. 6). The nalure of the wing deflection is well described with both analysis and experiment showing a bend-up, twist-down deformation. The corresponding results for a TEO control surface deflection of minus five degrecs, not presented here, compared better in terms of 
deflection, inches

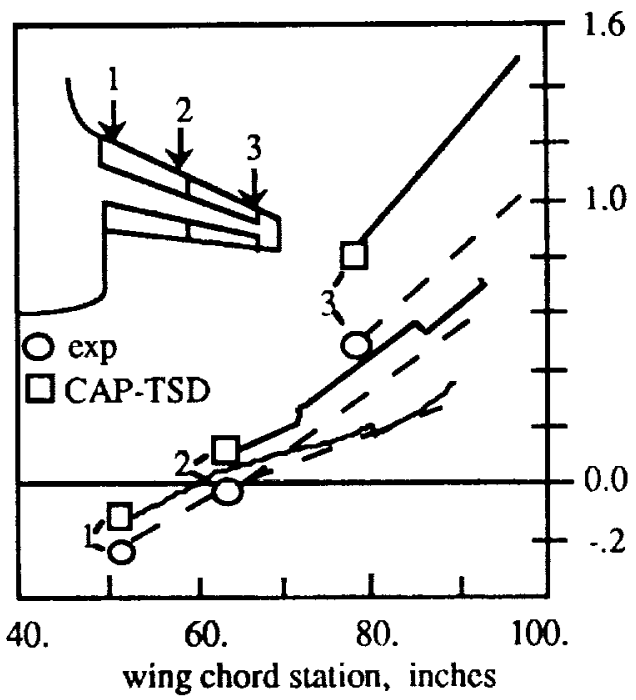

Fig. 7 Comparison of quasi-experimental and analytical static aeroelastic deflections, $M_{\infty}=0.9, q=150$ psf in the heavy gas.

the magnitude of deflections and moderately well in predicting the amount of twist at the wing tip. However, the resulting deformations (quasi-experimental and calculated) were much smaller for the minus five degree control surface deflection.

Based upon these results, the static aeroelastic solution is viewed as a reasonably accurate approach. The accuracy of the solution, when combined with control surface deflections, is diminished although the trends rcmain within reason. Mcthods for improving the static aeroelastic solution include the application of measured mode shapes (the present aeroclastic analyses uses analytical mode shapes with measured frequencies) and an increased number of mode shapes. Improvement of the control surface modelling may be possible by a finer grid at the control surface boundaries and limiting application to small deflection angles. This may only be valid for the leading-edge controls, since incorporation of boundary layer and separated flows will probably be necded for improvement in the modelling of the trailing-edge control surfaces .

\section{Dynamic Results}

Results in the Heayy Gas- The root locus of the first four clastic modes with nonlincar aerodynamics for $M_{\infty}=0.9$ and 1.5 degrees angle-of-attack with no viscous damping is presented in Figure 8. It should be mentioned that the wing tip ballast store is included in these results. The flutter mechanism involves the coalescence of the second (first bending) and third (first torsion) elastic modes resluting in a flutter dynamic pressure of $213 \mathrm{psf}$ and a flutter frequency of $9.7 \mathrm{~Hz}$. The branch of the root locus for first bending yields the flutter condition.

The resultant flutter boundary, Mach number versus flutter dynamic pressure, and corresponding flutter ircquencies, are shown in figure 9. A moderate transonic

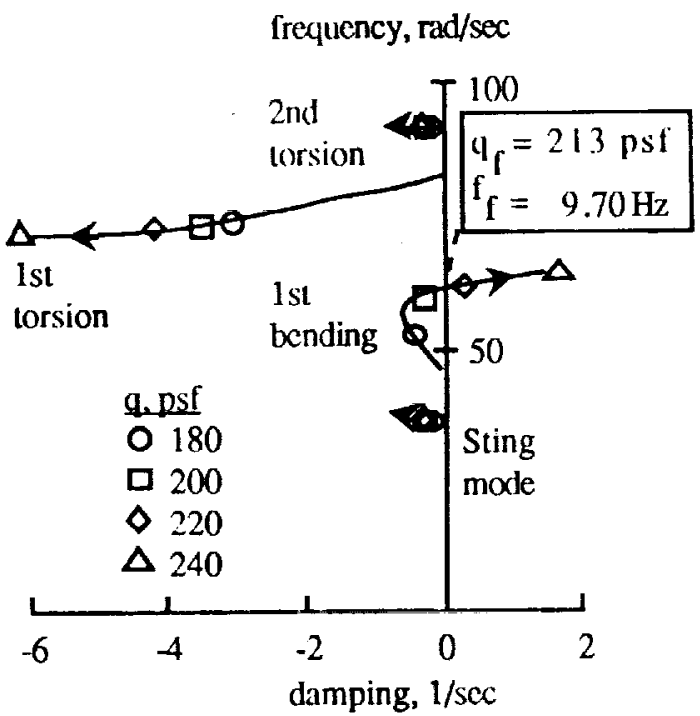

Fig. 8 Root locus of first four elastic modes with nonlinear aerodynamics, $\mathrm{M}_{\infty}=0.9$, alpha= $1.5 \mathrm{deg}$, and no viscous damping.

Hutter "dip" is evident, with the bottom of the "dip" at $\mathrm{M}_{\infty}=0.95$, a dynamic pressure of $153 \mathrm{psf}$ and a flutter frequency of $9.2 \mathrm{~Hz}$.

It is interesting to note that, in the flutter analysis with doublet lattice (linear) acrodynamics 15 , the predicted flutter mechanism is a torsion-dominated (third mode) instability for all Mach numbers analyzed in the heavy gas. The nonlinear aerodynamic terms are, therefore, altering the nature of the flutter mechanism from a torsion-dominated instability to a bending-dominated instability, as seen in Fig. 8 .

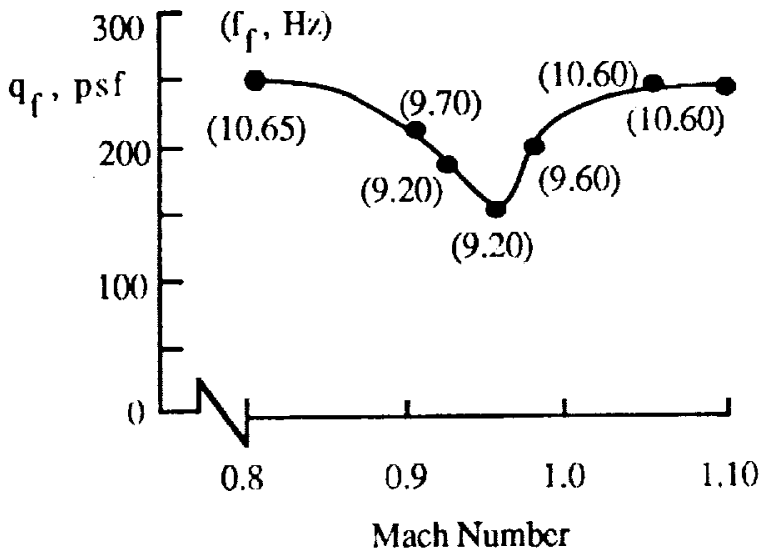

Fig. 9 Flutter boundary with nonlinear acrodynamics at alpha $=1.5 \mathrm{deg}$ and no viscous damping in the heavy gas. 


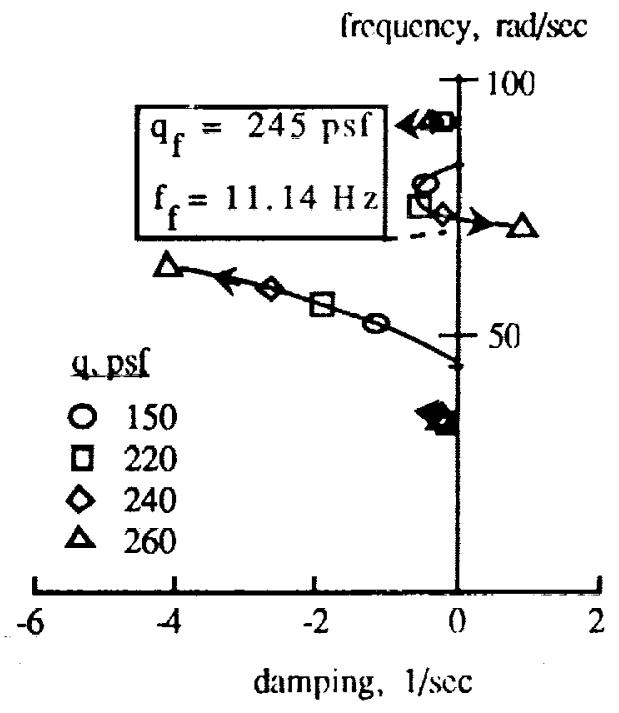

Fig. 10 Root locus of first four clastic modes with nonlinear aerodynamics at $\mathrm{M}_{\infty}=0.5$, alpha= $1.5 \mathrm{deg}$ and no viscous damping, in air.

Results in Air- Figure 10 is the root locus computed using nonlinear aerodynamics at $\mathrm{M}_{\infty}=0.5$ and 1.5 degrces angle-of-attack with no viscous damping. Although the aerodynamics at $\mathrm{M}_{\infty}=0.5$ are linear, the analysis was performed using the nonlinear acrodynamic equations so that the effect of the nonlinear terms on the flutter mechanism could be evaluated as Mach number was varied. Figure 10 shows the coalescence between the second and third modes, with the third mode (torsion) dominating the instability at a dynamic pressure of 245 psf and a flutter frequency of $11.14 \mathrm{~Hz}$. The flutter analysis using linear aerodynamics in air ${ }^{15}$ also predicted a torsion-dominated instability for all Mach numbers from $M_{\infty}=0.5$ to $M_{\infty}=0.9$ (highest Mach number evaluated). This implies that the nonlincar terms have little effect on the aerodynamics at $\mathrm{M}_{\infty}=0.5$, as expected.

The root locus for $M_{\infty}=0.85$ with nonlinear aerodynamics at 1.5 degrecs angle-of-attack and no viscous damping is shown in Fig. 11, with a flutter dynamic pressure of $204 \mathrm{psf}$ and a flutter frequency of $9.55 \mathrm{~Hz}$. At $M_{\infty}=0.85$, a reversal of the dominant flutter mode from a torsion-dominated instability $\left(\mathrm{M}_{\infty}=0.5\right)$ to a bendingdominated instability is noticed. Since the dominant flutter mode, predicted with linear acrodynamics, does not vary with Mach number, this reversal of the dominant flutter mode between $\mathrm{M}_{\infty}=0.5$ and $\mathrm{M}_{\infty}=0.85$ (and at $\mathrm{M}_{\infty}=0.9$ in the heavy gas), is a measure of the increasing sensitivity to differences in the acrodynamic modelling. As Mach number is further increased, the dominance of the bending futter mode continues to grow, as if approaching a single-degrec-of-frectom (bending) instability. This is consistent with the result by Isogail. Reference 1 shows that for a two-dimensional wing (with vibrational propertics similar to those of a typical, streamwise section of an aft-swcpt wing), the flutter mechanism at subsonic Mach numbers is the classical bending-torsion instability, driven by the phase Jag betwecn the two modes. As Mach number is increased, howcver, the phase lag between the two modes is gradually reduced to near zero, signaling the presence of a single-degrec-of-freedom motion, or bending in the case of Ref. 1.

Figure 12 is a plot of Mach number versus flutter dynamic pressure at 1.5 degrees angle-of-attack and no viscous damping. A scvere transonic flutter "dip" is present, with the bottom of the "dip" at $\mathrm{M}_{\infty}=0.93$, a dynamic pressure of $20 \mathrm{psf}$ and a flutter frequency of 7.16 $\mathrm{Hz}$. A variation in transonic flutter "dip" between air and the heavy gas is cxpected since, as Mykytow 24 pointed out, the greater the mass ratio, the greater the transonic flutter "dip". Reference 1 supports this statement by showing that increases in mass ratio drive the aeroelastic system towards an earlier onset of the nearly singledegrec-of-freedom instabilty. The AFW model in air experiences about double the mass ratio experienced in the heavy gas, and the effect of this increase in mass ratio can be seen in Figs. 8 and 11. The $M_{\infty}=0.85$ flutter mechanism in air (Fig. 11) exhibits a slightly stronger bending-dominated instability than the $\mathrm{M}_{\infty}=0.90$ Tlutter mechanism in the heavy gas (Fig. 8). However, the magnitude and stcepness of the "dip" in air is surprising.

Damping and angle-of-attack variations- The siructural damping of the AFW model was determined from GVT tests to be about $1.5 \%$ critical damping. In order to account for this, flutter analyses were performed at $\mathrm{M}_{\infty}=0.5,0.9,0.93$, and 0.95 with a viscous damping value of 0.015 for each mode. Note that the static acroclastic analysis for these cases did not have to be

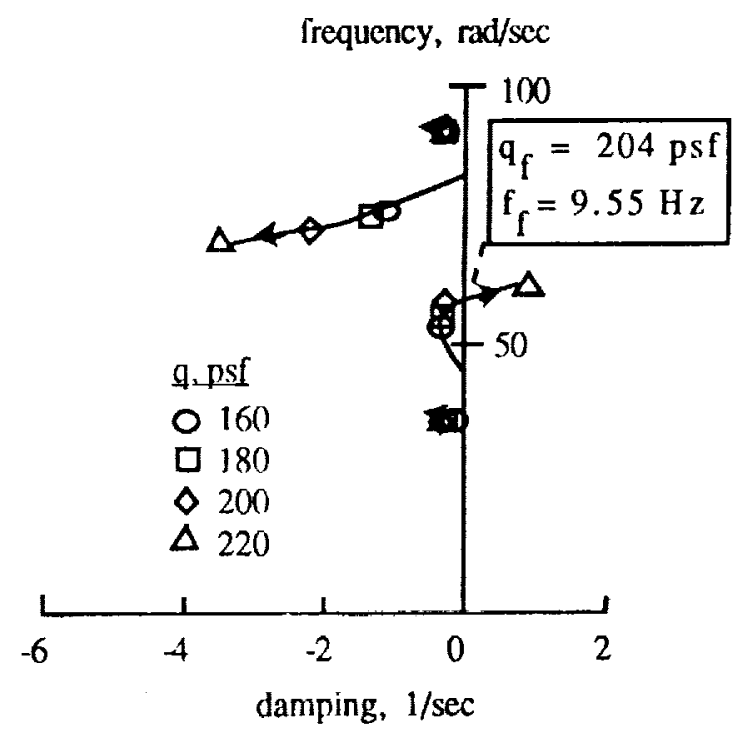

Fig. 11 Root locus for the first four clastic modes with nonlincar acrodynamics, $M_{\infty}=0.85$, alpha $=1.5 \mathrm{deg}$ and no viscous damping in air. 


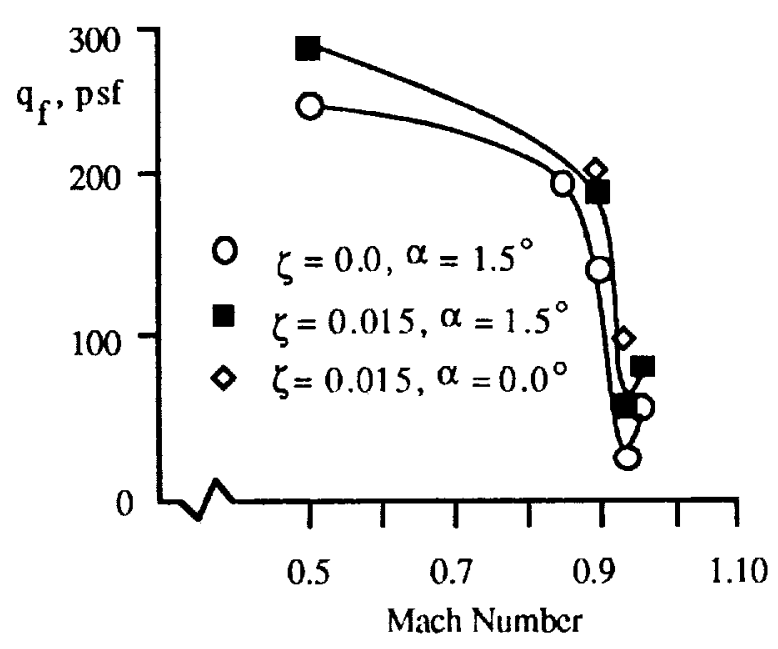

Fig. 12 Effect of viscous damping and angle-ofattack on the flutter boundary in air.

renun, since the viscous damping affects only the dynamic analysis. The flutter boundary including a viscous damping of 0.015 at 1.5 degrces angle-of-attack can also be seen in Fig. 12. The bottom of the "dip" is higher but still at $\mathrm{M}_{\infty}=0.93$, going from a dynamic pressure of 20 psf with no damping to $52 \mathrm{psf}$ with damping; an increase of $150 \%$. At $\mathrm{M}_{\infty}=0.5$, damping increased the flutter dynamic pressure by $50 \mathrm{psf}$ from $240 \mathrm{psf}$ to $290 \mathrm{psf}$, an increase of $21 \%$. At $\mathrm{M}_{\infty}=0.9$, the increase in flutter dynamic pressure due to damping is $50 \mathrm{psf}$, an increase of $36 \%$. Al $\mathrm{M}_{\infty}=0.95$, the increase in flutter dynamic pressure due to viscous damping is $62 \%$. from $50 \mathrm{psf}$ to $81 \mathrm{psf}$. Thus the calculated flutter boundary for the AFW in air is sensitive to damping, varying from a moderate sensitivity at $\mathrm{M}_{\infty}=0.50$ to a strong sensitivity at $\mathrm{M}_{\infty}=$ 0.93 .

In Fig. 12, the resultant flutter dynamic pressurcs at $\mathrm{M}_{\infty}=0.9$ and $\mathrm{M}_{\infty}=0.93$ for 0 degrees angle-of-attack and a viscous damping of 0.015 can also be scen. Decreasing the angle-of-attack from 1.5 to 0 degrees results in a slight stabilizing effect at $\mathrm{M}_{\infty}=0.9$ and a significant stabilizing effect at $M_{\infty}=0.93$. An angle-of-attack variation performed at $\mathrm{M}_{\infty}=0.5$ revealed no difference in flutter dynamic pressure, as would be expected.

\section{Experimental Results}

During wind-tunnel testing of the AFW, a subsonic flutter point was encountered at $\mathrm{M}_{\infty}=0.5$ and a $q=220$ psf, but it was considered to be antisymmetric and thus cannot be compared with the current symmetric analysis. It is speculated that the symmetric and antisymmetric flutter boundaries are separated subsonically with the antisymmetric set being the most flutter critical in this regime; the two instabilities appear to be close, however, at transonic Mach numbers.

During transonic flutter testing, threc flutter points in the Mach number range from 0.9 to 0.93 were encountered. Figure 13 presents the CAP-TSD predicted flutter boundary at 1.5 degrees and .015 viscous damping (Fig. 12), the predicted lincar (doublet lattice) flutter boundarics for symmetric and antisymmetric modes ${ }^{16}$, and the four experimental flutter points. The $M_{\infty}=0.9$ and $\mathrm{M}_{\infty}=0.93$ experimental points were also considered to be antisymmetric and are, again, not comparable with the present results. The $\mathrm{M}_{\infty}=0.92$ result, however, was identified as a symmetric instability, which compares extremely well with the CAP-TSD prediction. The experimental flutter frequency was about $8 \mathrm{~Hz}$ and the analytical flutter frequency was $7.8 \mathrm{~Hz}$. As Fig. 13 shows, the linear analyses predicted different trends with increasing Mach number.

The no-flutter track in the tunnel (shown in Fig. 13) indicales that the bottom of the experimental transonic flutter "dip" was at about $\mathrm{M}_{\infty}=0.93$ and a dynamic pressure of $146 \mathrm{ps} \Gamma$, much higher than that predicted by - CAP JTSD analysis. This is not all that surprising since the discrepancies between TSD theory and experiment that cxist in the heavy gas at $M_{\infty}=0.95$ could be occuring at $\mathrm{M}_{\infty}=0.93$ in air. That is, at $\mathrm{M}_{\infty}=0.93$ in air, the flow could be predominantly viscous, rendering TSD theory inadequate at this condition. Unfortunately, there is no pressure data in air to verify this. This would explain why CAP-TSD is accurate in the region between $\mathrm{M}_{\infty}=$ 0.9 and 0.92 (shocks, but possibly limited amounts of viscous flow) and why it is inaccurate at just a slightly higher Mach number, $M_{\infty}=0.93$, where viscous flow may be dominant. A conclusive answer to this discrepancy at $\mathrm{M}_{\infty}=0.93$ requires additional investigation.

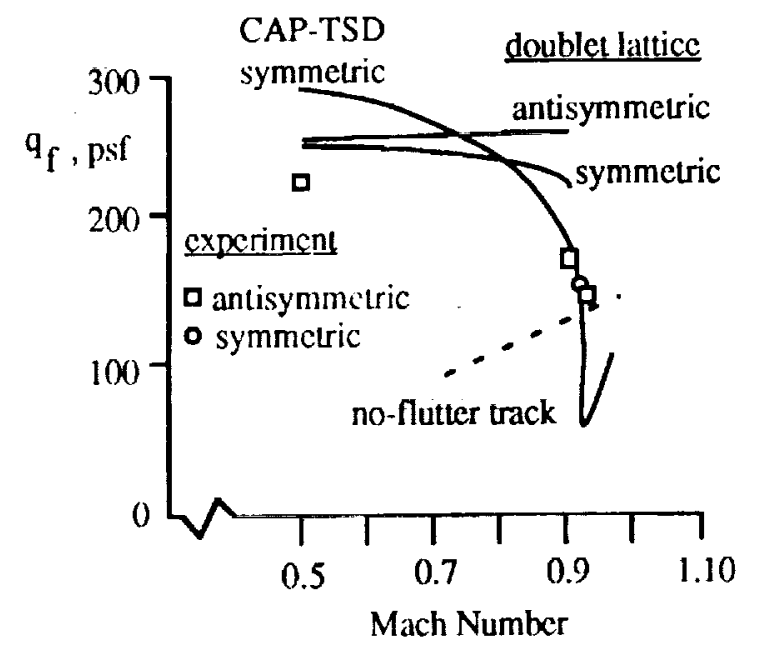

Fig. 13 Comparison of linear, nonlinear, and experimental flutter boundaries in air. 


\section{CONCLUSIONS}

The goal of this study was to define the transonic flutter boundary of the AFW wind-tunnel model, for guidance during futter testing, and to evaluate the flutter prediction capability of CAP-TSD for a complete and realistic configuration. The static aeroclastic and dynamic behavior of the AFW was investigated and compared with experiment.

The static acroelastic procedure developed was shown to be reasonably accurate. The accuracy of the procedure is reduced as control surfaces are dellected, probably due to viscous and vortex flows not addressed by TSD theory. As expected, the accuracy of the static aeroelastic solution at a given dynamic pressure and Mach number depends on how well the TSD assumptions represent the flow at that condition.

Flutter results in the heavy gas revealed a moderate transonic flutter dip at $M_{\infty}=0.95$, while the flutter boundary in air resulted in a stecp dip near $M_{\infty}=0.93$ due to the increase in mass ratio. The flutter boundary in air demonstrated increased sensitivity to damping and angleof-attack variations at transonic Mach numbers. The resultant flutter boundary provided valuable guidance during flutter testing of the AFW, as demonstrated by the excellent match between theory and experiment in air at $\mathrm{M}_{\infty}=0.92$. The CAP-TSD results at $\mathrm{M}_{\infty}=0.93$, however, were inaccurate. At this Mach number, viscous effects may be dominating the flow, rendering TSD theory inapplicable. Until viscous acroelastic codes arc fully developed, however, the use of the CAP-TSD code for predicting the transonic aeroelastic behavior of a flexible wind-tunnel model, the AFW, was very valuable.

\section{ACKNOWLEDGEMENT}

The authors would like to thank S. R. Bland, J. T. Batina, D. A. Seidel and S. R. Colc for their support and assistance.

\section{BEFERENCES}

I Isogai, K. : On the Transonic-Dip Mechanism of Flutter of a Sweptback Wing, AIAA Journal, Volume 17, Number 7, July 1979, pp. 793-795.

${ }^{2}$ Davis, S. S.; and Malcolm, G. N. : Experiments in Unsteady Transonic Flow, AIAA Paper Number 79-0769, AIAA/ASME/ASCE/AHS 20th Structures, Structural Dynamics, and Materials Conference, St. Louis, MO, April 4-6, 1979.

${ }^{3}$ Edwards, J. W.; and Thomas, J. L. : Computational Methods for Unsteady Transonic Flows, AIAA Paper Number 87-0157, Presented at the AIAA 25th Acrospace Sciences Mecting, Reno, NV, January 12-15, 1987.
${ }^{4}$ Ballhaus, W. F.; and Bridgeman, J. O. : Numcrical Solution Tcchniques for Unsteady Transonic Problems, AGARD Report Number 679, Paper Number 16, March 1980.

${ }^{5}$ Wu, J. C. ; Kaza, K. R. V.; and Sankar, N. L. : A Technique for the Prediction of Airfoil Flutter Characteristics in Separated Flows, AIAA Paper Number 87-0910, Presented at the AIAA/ASME/ ASCE/AHS 28th Structures, Structural Dynamics, and Matcrials Conference, Monterey, CA, April 6-8, 1987.

${ }^{6}$ Bendiksen, O. O.; and Kousen, K. : Transonic Flutter Analysis Using the Euler Equations, AIAA Paper Number 87-0911, Presented at the AIAA/ASME/ ASCE/AHS 28th Structures, Structural Dynamics, and Materials Conference, Monterey, CA, April 6-8, 1987.

${ }^{7}$ Shankar, V.; and Ide, H. : Unsteady Full Potential Computations Including Acroelastic Effects, Proceedings of the Sth International Conference on Numerical Methods in Laminar and Turbulent Flow, Volume 5, Part 2, Montrcal, Canada, July 6-10, 1987.

$8_{\text {Borland, C. J.; and Rizzetta, D. P. : Nonlinear }}$ Transonic Flutter Analysis, AIAA Journal, Volume 20, November 1982, pp. 1606-1615.

${ }^{9}$ Yang, T. Y.; Guruswamy, P.; and Striz, A, G. : Application of Transonic Codes to Flutter Analysis of Conventional and Supercritical Airfoils, AIAA Paper Number 81-0603. Proceedings of AIAA Dynamics Specialist Conference, Atlanta, GA, April 9-10, 1981, pp. 332-342.

${ }^{10}$ Batina, J. T. : Efficient Algorithm for Solution of the Unsteady Transonic Small-Disturbance Equation, Journal of Aircraft, Volume 25, July 1988, pp. 598-605.

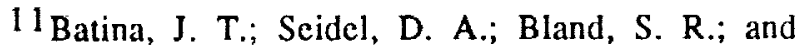
Bennell, R. M. : Unsteady Transonic Flow Calculations for Realistic Aircraft Configurations, Journal of Aircraft, Volume 26, January 1989, pp. 21-28.

12 Bennell, R. M.; Bland, S. R.; Batina, J. T.; Gibbons, M. D.; and Mabcy, D. G. : Calculation of Stcady and Unstcady Pressures on Wings at Supersonic Speeds with a Transonic Small-Disturbance Code, AIAA Paper Number 87-0851, Presented at the AIAA/ASME/ASCE/AHS 28th Structures, Structural Dynamics, and Materials Conference, Montercy, CA, April 6-8, 1987.

${ }^{13}$ Bennclt, R. M.; Batina,J. T.; and Cunningham,H. J. : Wing Flutter Calculations with the CAP-TSD Unstcady Transonic Small-Disturhance Program, Journal of Aircraft, Volume 26, Number 9, September 1989, pp. $876-882$. 
14 Miller, G. D. : Active Flexible Wing (AFW) Technology, AFWAL-TR-87-3096, Final Report for Period June 1985-May 1987, Fcbruary 1988.

15Perry, B. III, et al. : Digital-Flutter-SuppressionSystem Investigations for the Active Flexible Wing Wind-Tunnel Model, Paper Number 90-1074, Presented at the 31st Structures, Struclural Dynamics, and Materials Conference, Long Beach, CA, April 2-4, 1990.

16 Mukhopadhyay, V.; Perry, B. III; and Noll, T. E. : Flutter Suppression Control Law Synthesis for the Active Flexible Wing Model, Paper Number 89-059, Presented at the European Forum on Acroclasticity and Structural Dynamics, Aachen, FRG, April 17-19, 1989.

17Yates, E. C. Jr.; Wynne, E. C. ; and Farmer, M. G. : Mcasured and Calculated Effects of Angle of Attack on the Transonic Flutter of a Supercritical Wing, NASA TM 83276, August 1982.

18 Yates, E. C. Jr.; and Chu, L. : Static Aeroclastic Effects on the Flutter of a Supercritical Wing, NASA TM 89132, March 1987.

${ }^{19}$ Batina, J. T. : Unsteady Transonic Algorithm Improvements for Realistic Aircraft Applications, Journal of Aircrafi, Volume 26, February 1989, pp. 131-139.

${ }^{20}$ Batina, J. T. : Unsteady Transonic Small-Disturbance Theory Including Entropy and Vorticity Effects, Journal of Arcraft, Volume 26, Number 6, June 1989, pp. 531 538.

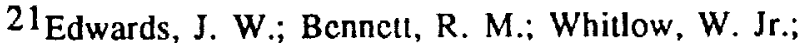
and Seidel, D. A. : Time-Marching Transonic Flutter Solutions Including Angle-of-Altack Effects, Journal of Aircraft, Volume 20, Number 11, November 1983, pp. 899-906.

${ }^{22}$ Bennett, R. M.; and Desmarais, R. N. : Curve Fitting of Aeroelastic Transient Response Data with Exponential Functions, In Flutter Testing Techniques, NASA SP-415, pp. 43-58, May 1975.

${ }^{23}$ Harder, R. L.; and Desmarais, R. N. : Intcrpolation Using Surface Splines, Journal of Aircraft, Volume 9, Fcbruary 1972, pp. 189-191.

${ }^{24}$ Mykytow, W. J. : A Brief Ovcrvicw of Transonic Flutter Problems, Unsteady Airloads in Separated and Transonic Flow, AGARD-CP.226, April 1977 , pp. 11-1-11-11. 


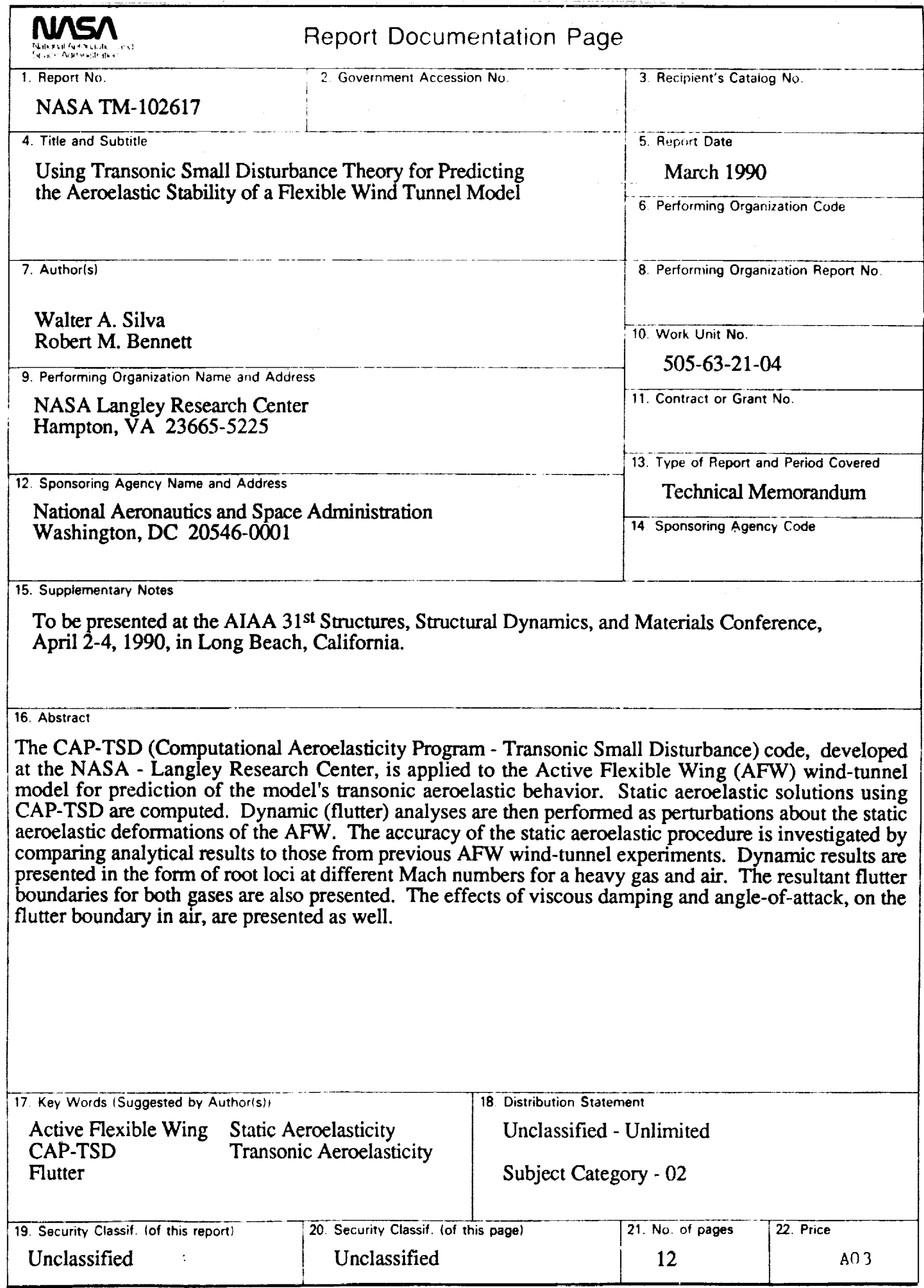

